\title{
Intermittent hypoxia reduces infarct size in rats with acute myocardial infarction: a systematic review and meta-analysis
}

\author{
Ke Hu${ }^{1}$, Wei Deng ${ }^{2 *}$, Jing Yang ${ }^{3}$, Yu Wei ${ }^{2}$, Chaolin Wen², Xingsheng $\mathrm{Li}^{2}$, Qingwei Chen², Dazhi Ke ${ }^{2}$ and \\ Guiqiong $\mathrm{Li}^{2}$
}

\begin{abstract}
Background: To determine whether intermittent hypoxia $(I H)$ can reduce the infarct size (IS) after acute myocardial infarction (AMI) in rats.

Methods: Articles were identified in PubMed, EMBASE and the Web of Science and were included if they evaluated the effect of $\mathrm{H}$ on the changes in the infarcted area after AMI in rats.

Results: A preliminary search identified 3633 articles and 29 data sets from 23 articles (12 in vivo, 16 in vitro). The IS decreased after AMI in $\mathrm{IH}$ rats both in vitro (SMD $\left.-1.46,95 \% \mathrm{Cl}[-2.37,-0.55] ; I^{2}=85.6 \%, P=0.000\right)$ and in vivo (SMD $-1.43,95 \% \mathrm{Cl}[-2.05,-0.82], \mathrm{I}^{2}=73.6 \%, P=0.000$ ). Sensitivity analysis indicated that $\mathrm{IH}$ had a strong protective effect against myocardial infarction, and the hypoxia concentration was significantly correlated with the change in IS after AMI.
\end{abstract}

Conclusion: $\mathrm{IH}$ can reduce IS after AMI in rats. This effect of $\mathrm{IH}$ may be related to the dose of hypoxia, and the oxygen concentration may be one of the most important influencing factors.

\section{Background}

Intermittent hypoxia $(\mathrm{IH})$ involves inducing the body to continuously self-regulate by repeatedly exposing the subject to a hypoxic or hypobaric hypoxia environment in a certain way $[1,2]$. To construct IH animal models, experimental animals such as rats or mice are repeatedly exposed to a hypoxic environment with controlled parameters (including oxygen concentration, air pressure, daily exposure time, total duration, and mode of action). The IH animals are then subjected to coronary artery ligation (20-30 $\mathrm{min})$ in vivo or in vitro. Next, the coronary artery is reperfused for $2-4 \mathrm{~h}$. Finally, the myocardial

\footnotetext{
* Correspondence: dengwei1176@hospital.cqmu.edu.cn

${ }^{2}$ Department of Geriatrics, The Second Affiliated Hospital of Chongqing Medical University, No. 74, Linjiang Road, Yuzhong District, Chongqing 400010, China

Full list of author information is available at the end of the article
}

infarct area of the rats is observed and compared with a normoxic group [3, 4].

An increasing number of studies show that $\mathrm{IH}$ can help reduce the area of myocardial infarction in patients with coronary heart disease [5-7] or in animal models of acute myocardial infarction $[8,9]$. IH can not only reduce IS but also increase the ejection fraction of the heart and reduce the occurrence of arrhythmia after AMI $[8,10,11]$, IH also has protective effects on other organs of the body, such as lowering blood pressure, improving glucose tolerance, improving blood lipid levels, reducing the infarct area after acute cerebral infarction, and improving cognitive dysfunction and renal fibrosis after ischemia [1, 2, 12-15].

However, researchers also found that $\mathrm{IH}$ sometimes increases myocardial IS after AMI in rats [16, 17]. Therefore, we conducted a comprehensive systematic review and meta-analysis to evaluate whether the overall 
effect of intermittent hypoxia on the heart increases or decreases the IS. Multiple subgroup analyses were also performed to further explore how the details of the $\mathrm{IH}$ protocol influence the findings. At the same time, this meta-analysis assesses how the robustness of the data analysis and the quality and publication bias of the literature included in the study will impact the findings and overall conclusions.

\section{Methods}

\section{Literature search}

The systematic review was conducted according to the Preferred Reporting Items for Systematic Reviews and Meta-Analyses (PRISMA) guidelines [18]. $\mathrm{Ke} \mathrm{Hu}$ and Jing Yang performed a literature search of the EMBASE, Medline (PubMed) and Web of Science databases using selected keywords (Heart, Myocardial Infarction, Myocardial Ischemia, Coronary Artery Disease, Myocardial Reperfusion Injury, Myocardium, Hypoxia, Oxygen Deficiency, Altitude, Rat) and Medical Subject Headings $(\mathrm{MeSH})$ terms specific to each database.

The search included literature that investigated the effect of IH on infarct size in either in vivo (in which the coronary artery is occluded in living anesthetized rat hearts) and in vitro (in which the coronary artery is occluded in isolated rat hearts) models after AMI. Searches were performed on October 31, 2019, and included only studies that were available in English. The inclusion criteria were developed in accordance with the PICOS (population, intervention, comparison, outcome, study design) approach [19]. In vivo and in vitro studies were included, and the oxygen concentration, daily duration and total time of $\mathrm{IH}$ should also be described in detail. The duration of ischemia and reperfusion should also be recorded.

The following classes of studies were excluded: studies that used persistent $\mathrm{IH}$; studies in which there was no documented reperfusion phase or the coronary artery occlusion was permanent; studies that did not report absolute myocardial IS as a percentage of ventricle size (VS) or area at risk (AAR, defined as the myocardial tissue within the vascular territory that is distal to the occluded artery and, if not reperfused, is at risk of irreversible ischemic death); studies employing genetically modified animals or animals with comorbidity, such as diabetes, heart failure, or high blood pressure; and experimental studies where an IH was administered concomitantly with any other pharmacological treatment, whether it is known for its cardioprotective properties or not.

\section{Data extraction and quality assessment}

Data were independently extracted by two authors ( $\mathrm{Yu}$ Wei and Chaoling Wen) using a predesigned table, including first author's name, year of publication, species, age, sex, hypoxic conditions, ligation of coronary artery, duration of index ischemia, reperfusion duration, induction anesthetic, measurement of IS, sample size, infarct size and variance. Disagreements were resolved by consensus in all cases. Whenever key information was missing, we contacted the report authors by e-mail and requested it. We characterized the quality of reporting in the included studies using a predefined 20-point scoring scale based on the Animal Research: Reporting In Vivo Experiments (ARRIVE) guidelines [20, 21] and a 9point document quality scoring scale based on the Collaborative Approach to Meta-Analysis and Review of Animal Data from Experimental Studies (CAMARADES) list [22, 23]. This evaluation was carried out by $\mathrm{Ke} \mathrm{Hu}$ and Jing Yang independently. Disagreements were resolved by examining the full text of the article or by reaching consensus between reviewers in all cases.

\section{Statistical analysis}

Stata (version 14.0) was used for all statistical analyses. Whenever outcomes in infarct size were reported on different measurement scales, our primary outcome was expressed as standardized mean difference (SMD) between both experimental groups. The final effect values were expressed as a raw difference in the mean IS/VS\% or IS/AAR\% (the mean of the control groups minus the mean of the experimental group) and the corresponding 95\% confidence intervals (CI). The Q test was used to assess the magnitude of the heterogeneity between studies, with values $p<0.1$ or $\mathrm{I}^{2}>50 \%$ taken to indicate a moderate-to-high degree of heterogeneity. When $\mathrm{I}^{2}$ is greater than $50 \%$, a random effect model is used; otherwise, a fixed effect model is employed.

Sensitivity analysis was tested by conducting an additional stratified meta-analysis using the unstandardized mean difference (WMD). Furthermore, subgroup analyses based on predefined experimental factors were also performed.

We assessed the possibility of publication bias using Begg's test and defined significant publication bias as a $P$ value $<0.1$. A trim-and-fill computation was used to estimate the effect of publication bias on the interpretation of the results.

\section{Results}

Study selection process

Our preliminary search of three databases identified 4866 documents. After removing 2176 duplicates, we then removed 2358 articles based on their titles, after which 332 articles entered the summary screening stage and 59 articles entered the full-text screening. Ultimately, 23 papers including a total of 28 comparisons were collected. The data were divided into an in vivo group and an in vitro group (Fig. 1, Table 1). 


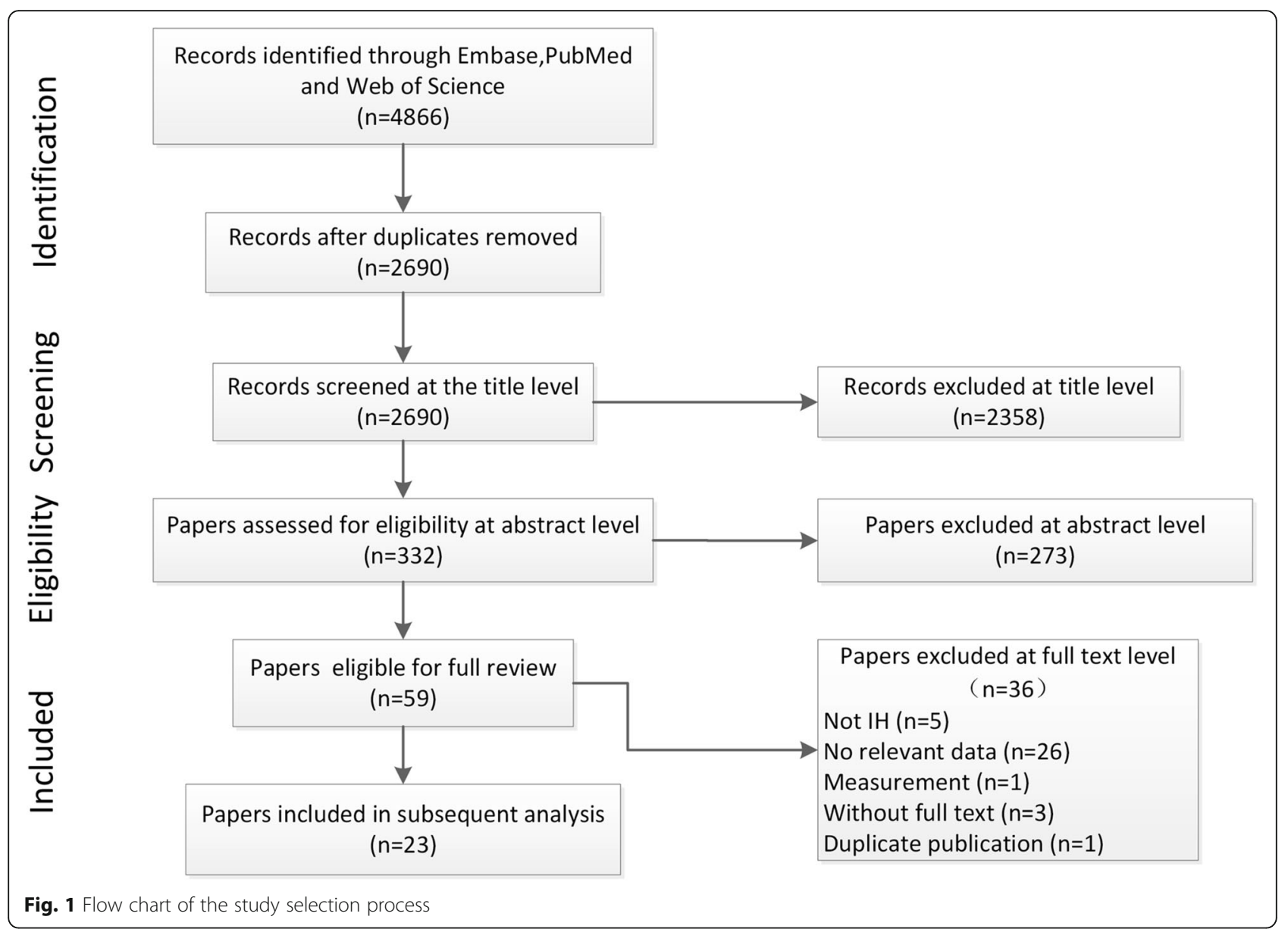

\section{Meta-analysis}

The meta-analysis showed that IH reduced IS after AMI both in vitro group (SMD -1.46, 95\% CI [-2.37, - 0.55]; $\mathrm{I}^{2}=85.6 \%, P=0.000$; Fig. 2 ) and in vivo group (SMD $-1.43, \mathrm{CI}[-2.05,-0.82], \mathrm{I}^{2}=73.6 \%, P=0.000$; Fig. 3 ).

\section{Sensitivity analysis}

WMD was used to rerun the meta-analysis, it showed similar results in vitro group (WMD -9.13, 95\% CI [$\left.14.67,-3.60], \mathrm{I}^{2}=92.3 \%, P=0.000\right)$ and in vivo group (WMD -14.026, 95\% Cl [-20.39, - 7.67], $\mathrm{I}^{2}=85.2 \%, P=$ 0.000 ). Subgroup analysis including oxygen concentration, daily hypoxic exposure, total stimulus duration, ligation of coronary artery and measurement of IS, species were made subsequently both in the in vitro group and in the in vivo group. In the in vitro group, data was grouped by the level of oxygen concentration $\left(\mathrm{FiO}_{2} \leq 5\right.$, $5 \%<\mathrm{FiO}_{2} \leq 10 \%, \mathrm{FiO}_{2}>10 \%$ ), showed a significant reduction in heterogeneity in each subgroup (Respectively $\mathrm{I}^{2}=0 \%, P=0.386$; Group B, $\mathrm{I}^{2}=32.1 \%, P=0.195$; Group C, $\mathrm{I}^{2}=58.3 \%, P=0.026$; Fig. 4a).

\section{Quality assessment and risk of bias}

We evaluated the quality of the included literature using a 20-point document quality scoring scale (Fig. 5a) based on the ARRIVE guideline and a 9-point document quality scoring scale (Fig. 5b) based on the CAMARADES list.

At the same time, Begg's test was used to evaluate publication bias. Within the in vitro group, there was significant publication bias ( $P=0.011$, Fig. $6 a)$, and trimand-fill computation was then used to detect the effect of publication bias on the results. The results showed no changes in the final conclusion. Within the in vivo group, there was no publication bias $(P=0.554$, Fig. $6 \mathrm{~b})$.

\section{Discussion}

The results of this meta-analysis suggest that appropriate $\mathrm{IH}$ reduces myocardial infarction size after AMI in rats. Among the conditions of $\mathrm{IH}$, oxygen concentration is one of the most important factors.

The analysis also suggest a high degree of heterogeneity among the included studies; therefore, we conducted further subgroup analyses to identify sources of heterogeneity. We used subgroup analysis to investigate the 


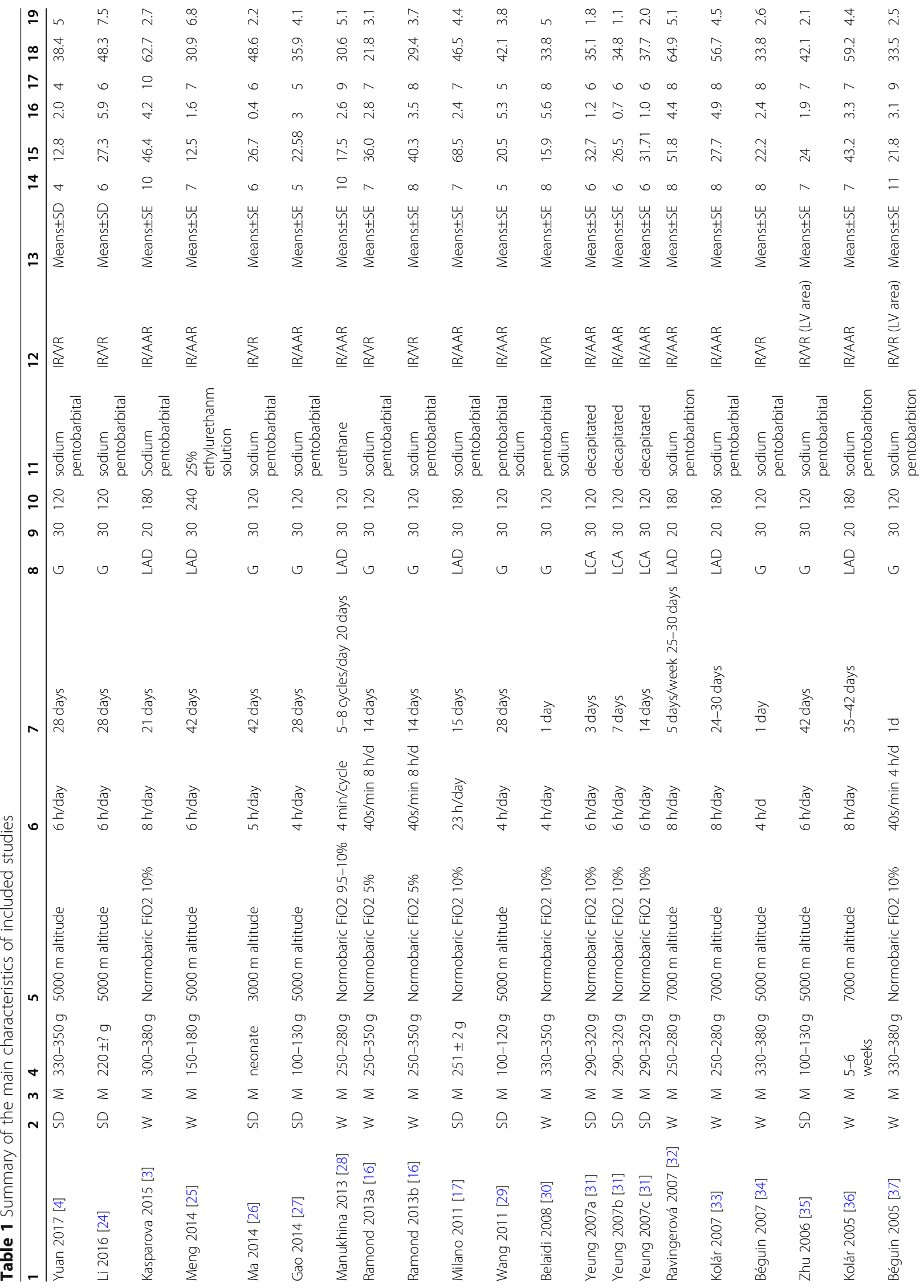




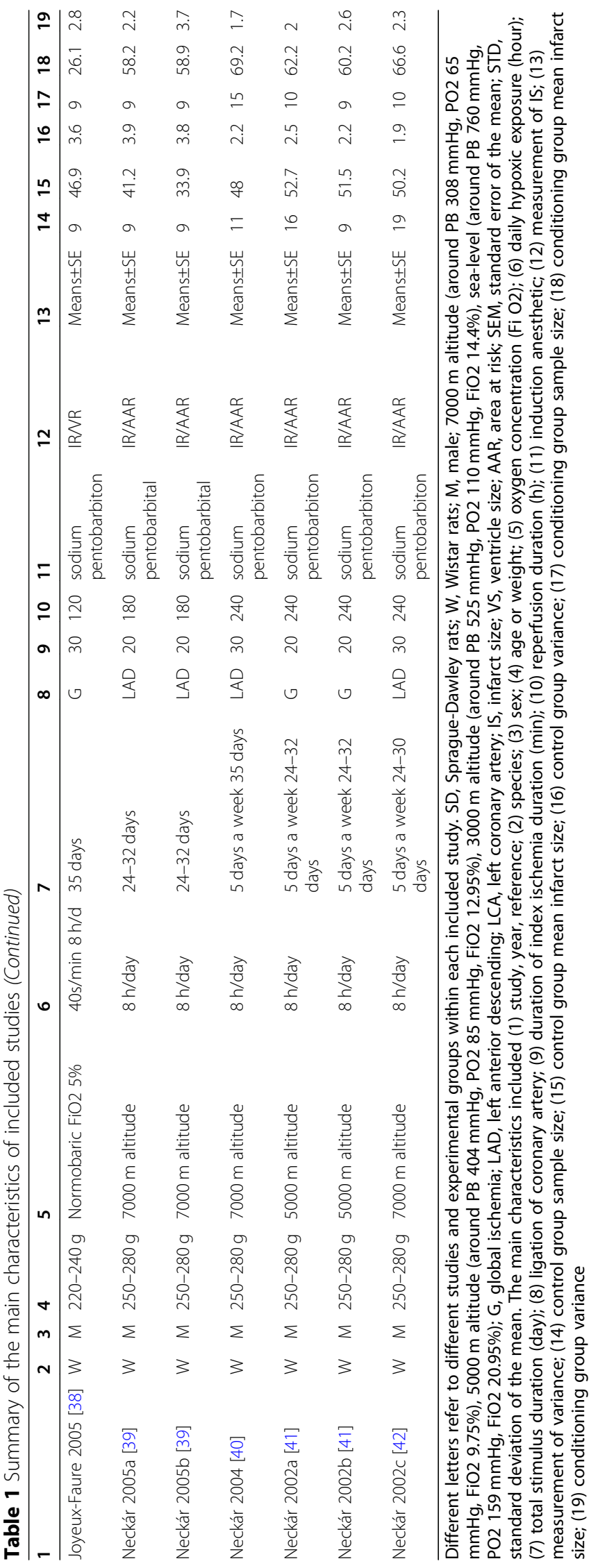




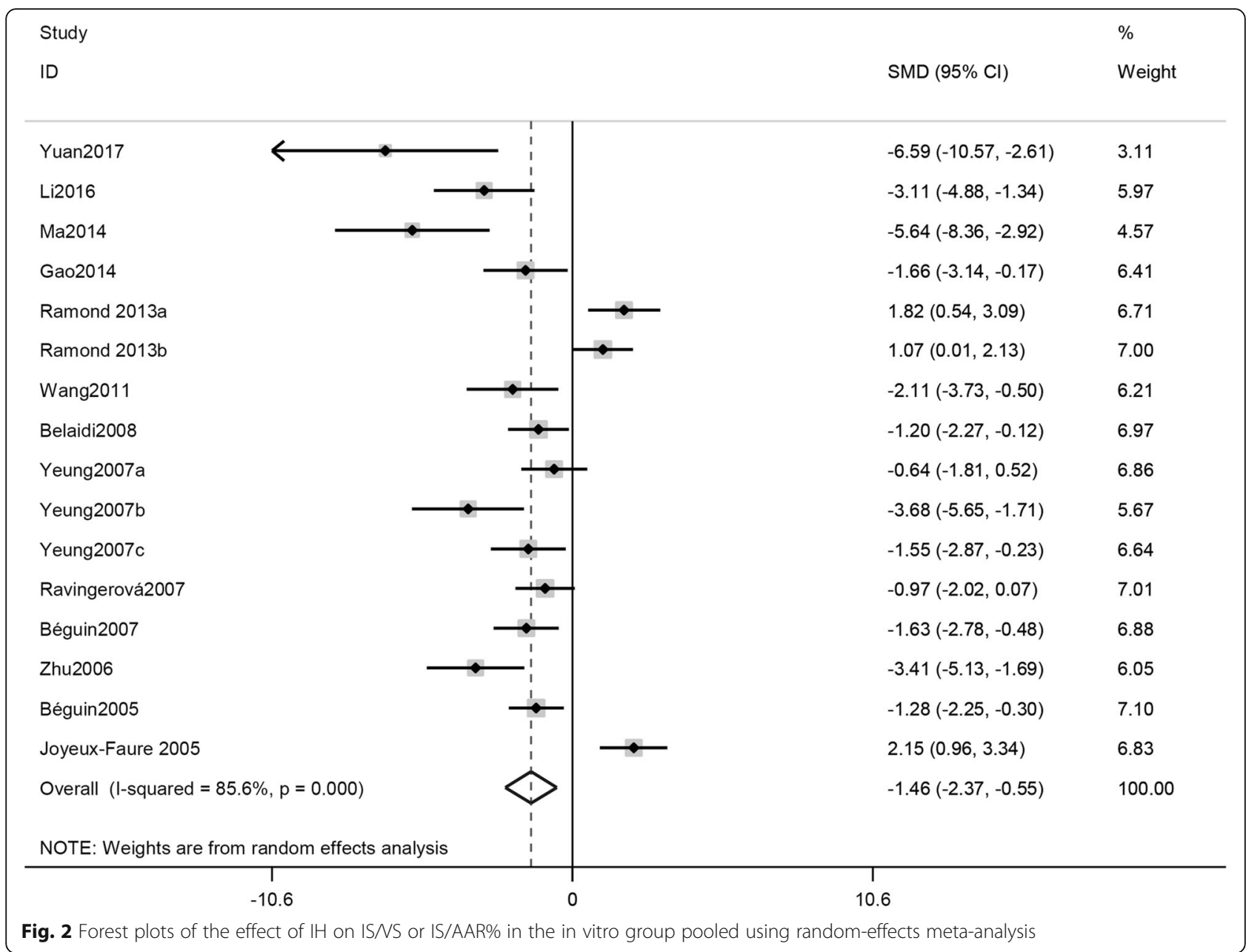

effects of oxygen concentration, daily exposure time, total days of exposure, ligation of coronary artery and measurement of IS, species on myocardial infarction area after acute hypoxia in rats.

In the in vitro group, hypoxic concentrations $\leq 5 \%$, $\leq 10$, and $>10 \%$ were grouped, and the heterogeneity between the groups was significantly lower than before. Further sensitivity analysis showed that the results were credible. We also performed a subgroup analysis on the ligation of coronary artery and measurement of IS subgroups in the in vitro group, and the results of the G/ (IS/VS) group also showed a high degree of heterogeneity. Thus, we conducted a further subgroup analysis of the hypoxia concentration in this subgroup (Supplementary material; Figure 1), and it suggested that the heterogeneity among the subgroups was significantly reduced. Similarly, through analysis of the species of rats in the in vitro group, the results in the Wistar rats group indicated that intermittent hypoxia might not reduce the area of myocardial infarction. Then we conducted a further subgroup analysis of the hypoxia concentration in this subgroup and found that the heterogeneity of each group was significantly reduced (Supplementary material; Figure 2), indicating that oxygen concentration may be an important factor in determining whether intermittent hypoxia can reduce the area of acute myocardial infarction in rats.

Thus, oxygen concentrations may be a source of heterogeneity and one of the main factors affecting the change in myocardial infarction size. Slightly higher hypoxic concentrations are more beneficial, and an excessively low oxygen concentration $\left(\mathrm{FiO}_{2}=5 \%\right)$ increases the IS after myocardial infarction in rats, suggesting that the protective effect of $\mathrm{IH}$ on the heart requires appropriate hypoxic concentrations. The lower limit for the oxygen concentration $\left(\mathrm{FiO}_{2}\right)$ may be between 5 and $9.5 \%$, and the exact lower limit needs further experimental research.

The subgroup analysis of daily hypoxic exposure suggests that daily hypoxia of $4 \mathrm{~h}, 6 \mathrm{~h}$, and $8 \mathrm{~h}$ can reduce the area of myocardial infarction after acute myocardial infarction in rats. Notably, the protective effect of 


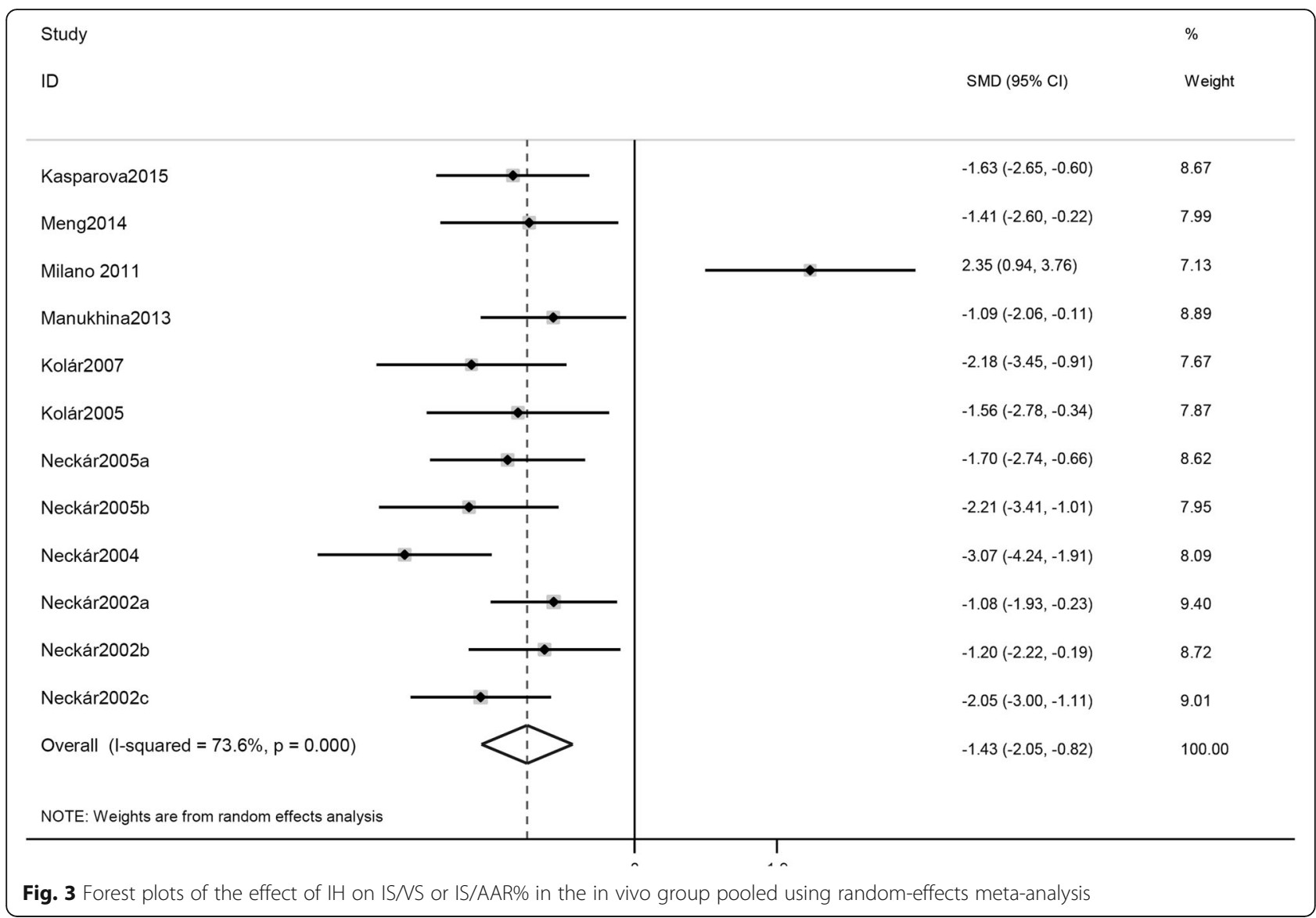

intermittent hypoxia on the heart is also observed with less than $1 \mathrm{~h}$ of daily hypoxia, and daily hypoxia for $23 \mathrm{~h}$ may increase the area of myocardial infarction.

Additionally, within the in vitro group, subgroups were defined on the basis of total duration ( $\leq 7$ days, $\leq 30$ days, and $>30$ days); the subgroup with a total duration $\leq 1$ week showed a reduction in IS after myocardial infarction. Does this result suggest that short-term hypoxia, perhaps even a single day of hypoxic treatment, can protect the heart? Further research is needed to confirm this conclusion. Short-term hypoxia, if effective, will facilitate the clinical application of IH for AMI and improve patient compliance compared to long-term protocols.

Above all, different hypoxic conditions have different effects on the heart. To clearly propose the treatment standard for intermittent hypoxia in the future, the concept of hypoxic dose which is the result of multiplying the oxygen concentration, daily exposure time, and total number of days should be introduced. However, the current researches are too deficient to clarify the hypoxic dose. Therefore, future research should explore the beneficial range of oxygen concentrations, daily durations, and total days, and then clarify the optimal dose of IH. Researchers must also pay attention to the effect of altitude (atmospheric pressure) and mode of action. Furthermore, the protective effect of intermittent hypoxia on the heart in rats disappeared after 90 days of recovery in a normal oxygen concentration environment [40], therefore, the effective course of hypoxic treatment should be clarified. Moreover, IH can be seen as a specific method of ischemic preconditioning of the myocardium [43], which reduces ischemia-reperfusion injury through a variety of cytokines and signaling pathways, further researches are needed to clarify the mechanism.

\section{Document quality and publication bias}

We also assessed the quality and publication bias of the research literature included in this analysis and assessed their impact on the final outcome. Most of the blinded ischemic and blinded results in the experimental procedure were not clearly described, which may increase the estimated IS after myocardial infarction in rats, thereby increasing the effect size. Additionally, descriptions of factors such as experimental design, rat feeding, rat allocation, and adverse events were described with little detail, if at all, and it was difficult to determine whether some of the lower-quality studies strictly applied highquality experimental design. These factors may be the 

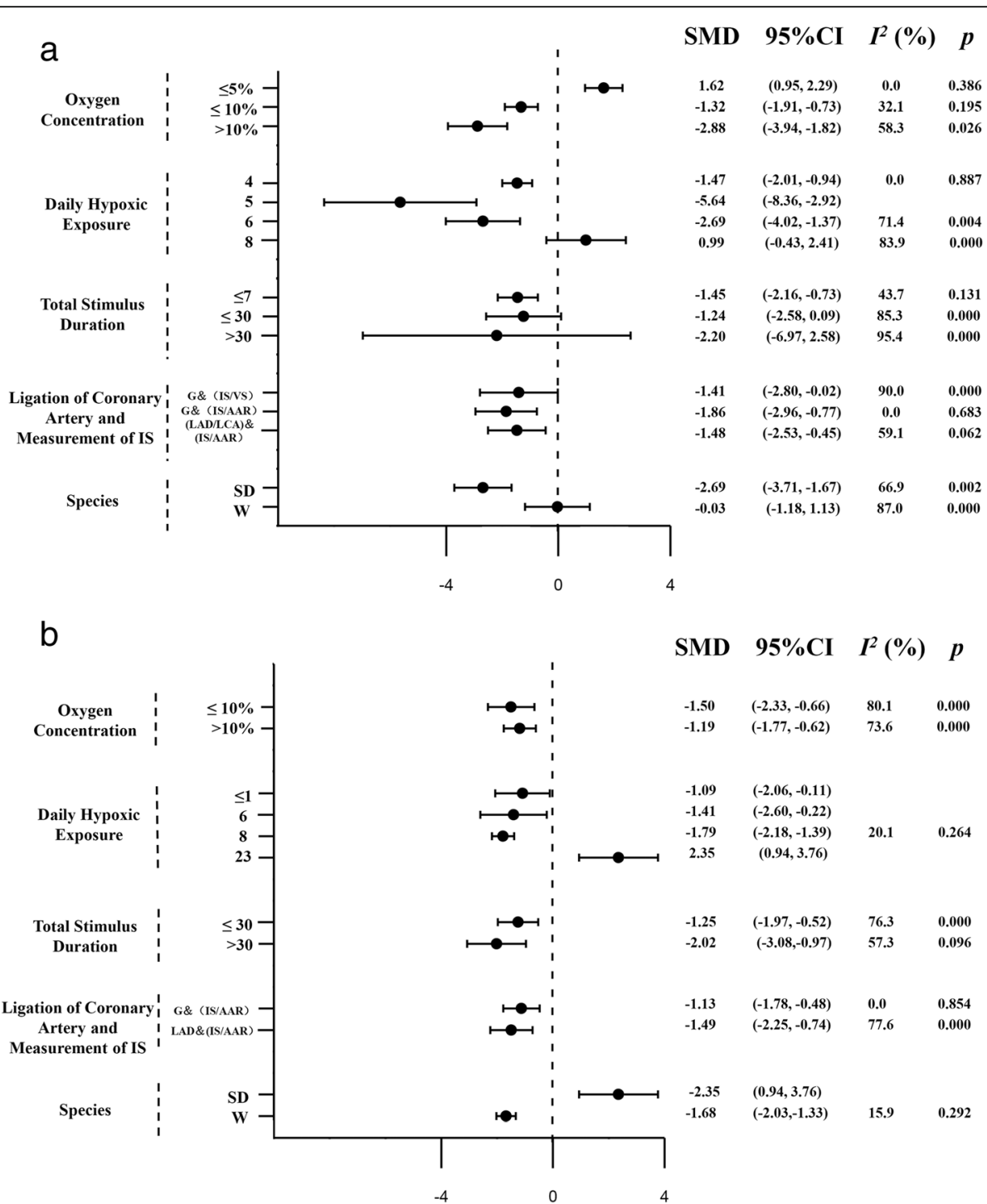

Fig. 4 Subgroup analysis of the effect on the vitro group (a) and the vivo group (b). Experimental variables are used to obtain the weighted standard mean difference along with the corresponding 95\% confidence interval $(95 \% \mathrm{Cl})$ followed. However, the reported $\mathrm{I}^{2}$ and $P$-value was obtained by $Q$ test, with values $I^{2}>50 \%$ or $P<0.1$ taken to indicate moderate-to-high heterogeneity

source of this heterogeneity in the analysis. Begg's test showed that significant publication bias was present within the in vitro group. The source of this publication bias may be that some negative results were not published.

\section{Limitations}

Since estrogen can potentially protect or damage the heart [44-46], the subjects we included were male rats. In addition, age may also have an effect on the infarct size after acute myocardial infarction in rats. However, there are too few studies using newborn rats as experimental subjects, and more intermittent hypoxia and agerelated studies are expected. This systematic review uses inclusion and exclusion criteria for literature screening but does not include articles published in other languages or unpublished articles in any language. There were also a small number of documents for which we failed to find the full text; these documents were excluded.

\section{Conclusion}

This systematic review showed that $\mathrm{IH}$ can reduce the infarct size after AMI in rats. Despite the high degree of heterogeneity, sensitivity analysis confirmed that the results were reliable, and hypoxia concentration may be one of the most important factors. We expect that IH will be an effective adjuvant treatment for patients with coronary heart disease and can improve systemic organ 
a

\section{Title \\ Abstract \\ Background}

Objectives

Ethical statement

Study design

Experimental procedures

Experimental animals

Housing and husbandry

Sample size

Allocating animals to experimental group

Experimental outcomes

Statistical methods

Baseline data

Numbers analysed

Outcomes and estimation

Adverse events

Interpretation/scientific implications

Generalizability/translation

Funding
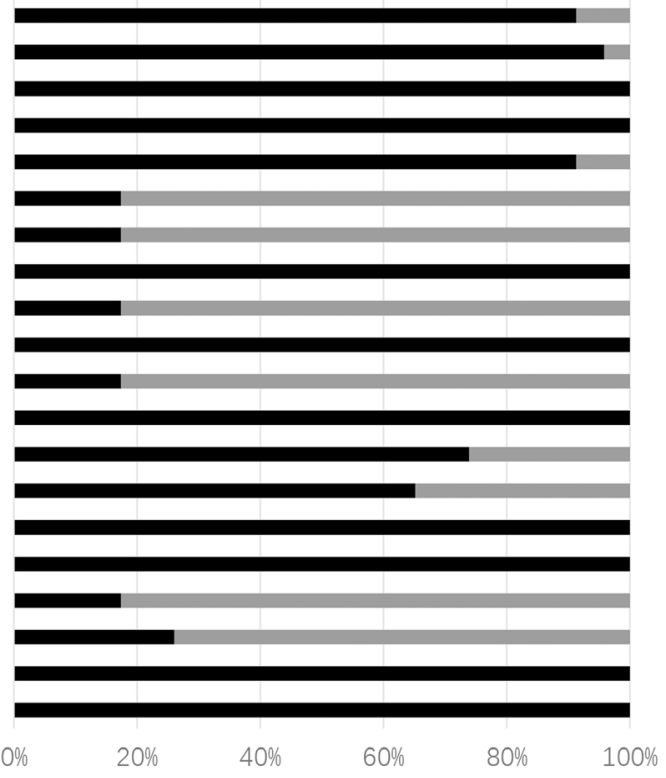

b

-YES $\quad$ NO

Publication in peer-review journal Compliance with regulatory requirement

Randomization

Statement of control of temperature Method of confirmation of ischemia

Blinded induction of ischemia

Blinded assessment of outcome

Sample size calculation

Statement of conflict of interest

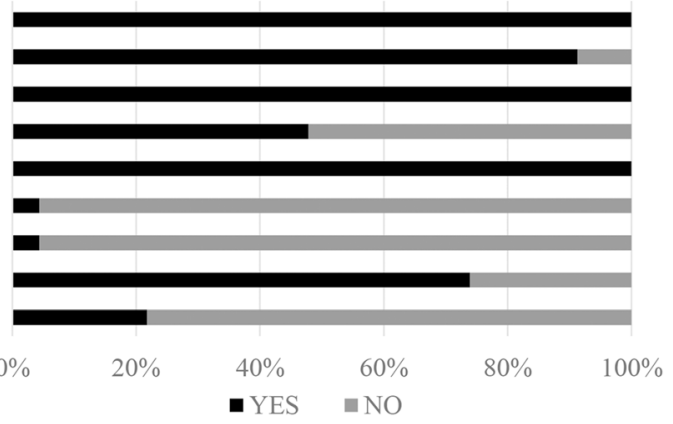

Fig. 5 Study quality assessment. A 20-point document quality scoring scale (a) based on the ARRIVE guidelines and a 9-point document quality scoring scale (b) based on the CAMARADES list. Values are expressed as the percentage of studies reporting each quality indicator 

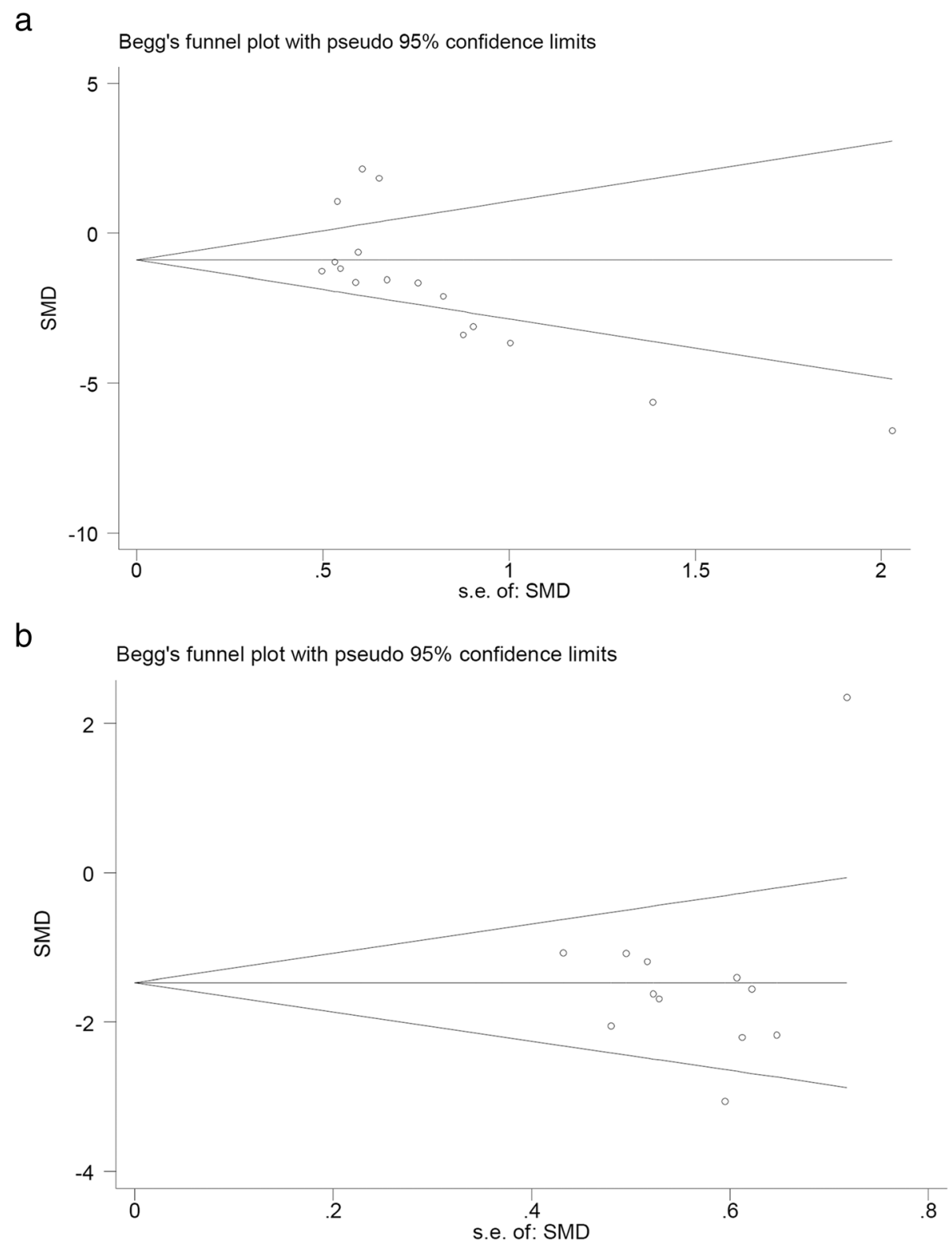

Fig. 6 Publication bias detection in the in vitro group (a) and in the in vivo group (b). Begg's test is used to help to assess for bias

function. Future research should further explore the mechanism of action of $\mathrm{IH}$, identify the optimal doses of IH suitable for various organs and tissues throughout the body, include large mammals and animals with comorbidities, and, finally, guide the application of $\mathrm{IH}$ in the clinic.

\section{Supplementary information}

Supplementary information accompanies this paper at https://doi.org/10. 1186/s12872-020-01702-y.

Additional file 1.

Additional file 2.
Additional file 3.

\section{Abbreviations}

IH: Intermittent hypoxia; IS: Infarct size; AMI: Acute myocardial infarction;

$\mathrm{Cl}$ : Confidence interval; VS: Ventricle size; AAR: Area at risk

\section{Acknowledgements}

None.

Authors' contributions

K.H, W.D. conception and design of research; K.H, J.Y. literature search; Y.W, C.-L.W. data extraction; K.H, J.Y. analyzed data; K.H drafted manuscript; W.D, X.-S. L edited and revised manuscript; Q.-W.C, G.-Q. L, D.-Z. K. approved final version of Manuscript. All authors have read and approved the manuscript. 


\section{Funding}

This work was supported by National Nature Science Foundation of China 81201101, Research program of Chongqing Education Assessment Research Association YJPH2012037, General research program on basic and frontier of Chongqing Science and Technology Commission cstc2015jcyjA10074, Chongqing Municipal Health Planning Commission Medical Research Project 2015MSXM019, Chongqing Municipal Education Commission project 17SKG022, Chongqing Municipal Education Commission Community Education Research Funding SJ2018-001, Chongqing Municipal Education Commission project 20SKGH029. Some financial assistance for literature access was obtained from these fundings. The funders played no role in study design, data extraction, analysis, and final write up.

\section{Availability of data and materials}

The datasets generated and analyzed during the current study are available from the corresponding author on reasonable request.

\section{Ethics approval and consent to participate}

Not applicable.

\section{Consent for publication}

Not applicable.

\section{Competing interests}

The authors declare that they have no competing interests.

\section{Author details}

'Department of Nephrology, The Second Affiliated Hospital of Chongqing Medical University, No. 74, Linjiang Road, Yuzhong District, Chongqing 400010, China. ${ }^{2}$ Department of Geriatrics, The Second Affiliated Hospital of Chongqing Medical University, No. 74, Linjiang Road, Yuzhong District, Chongqing 400010, China. ${ }^{3}$ Department of Neurology, The Second Affiliated Hospital of Chongqing Medical University, No. 74, Linjiang Road, Yuzhong District, Chongqing 400010, China.

Received: 12 February 2020 Accepted: 9 September 2020 Published online: 22 September 2020

\section{References}

1. Navarrete-Opazo A, Mitchell GS. Therapeutic potential of intermittent hypoxia: a matter of dose. Am J Physiol Regul Integr Comp Physiol. 2014; 307:R1181-97.

2. Almendros I, Wang Y, Gozal D. The polymorphic and contradictory aspects of intermittent hypoxia. Am J Physiol Lung Cell Mol Physiol. 2014;307:L12940.

3. Kasparova D, Neckar J, Dabrowska L, Novotny J, Mraz J, Kolar F, et al. Cardioprotective and nonprotective regimens of chronic hypoxia diversely affect the myocardial antioxidant systems. Physiol Genomics. 2015;47:61220.

4. Yuan F, Zhang L, Li YQ, Teng X, Tian SY, Wang XR, et al. Chronic intermittent hypobaric hypoxia improves cardiac function through inhibition of endoplasmic reticulum stress. Sci Rep. 2017;7(1):7922.

5. Rachok LV, Dubovik TA. Effects of adaptation to intermittent normobaric hypoxia in the patients with ischemic cardiomyopathy. Eur J Heart Fail. 2016;18:207-8

6. Shah N, Redline S, Yaggi HK, Wu R, Zhao CG, Ostfeld R, et al. Obstructive sleep apnea and acute myocardial infarction severity: ischemic preconditioning? Sleep Breath. 2013;17(2):819-26.

7. Ehrenburg I, Tkatchouk E, Burtscher M. Interval hypoxic training in rehabilitation of patients with coronary artery disease. Sleep and Breathing. 2012;16:250

8. Estrada JA, Williams AG Jr, Sun J, Gonzalez L, Downey HF, Caffrey JL, et al. Delta-opioid receptor (DOR) signaling and reactive oxygen species (ROS) mediate intermittent hypoxia induced protection of canine myocardium. Basic Res Cardiol. 2016;111(2):17.

9. Zong P, Setty S, Sun W, Martinez R, Tune JD, Ehrenburg IV, et al. Intermittent hypoxic training protects canine myocardium from infarction. Exp Biol Med (Maywood). 2004;229(8):806-12.

10. Aguilar M, Gonzalez-Candia A, Rodriguez J, Carrasco-Pozo C, Canas D, Garcia-Herrera C, et al. Mechanisms of cardiovascular protection associated with intermittent hypobaric hypoxia exposure in a rat model: role of oxidative stress. Int J Mol Sci. 2018;19(2):366.

11. Kohutova J, Elsnicova B, Holzerova K, Neckar J, Sebesta O, Jezkova J, et al. Anti-arrhythmic cardiac phenotype elicited by chronic intermittent hypoxia is associated with alterations in Connexin-43 expression, phosphorylation, and distribution. Front Endocrinol. 2018:9:789.

12. Sun $H$, Zhang H, Li K, Wu H, Zhan X, Fang F, et al. ESM-1 promotes adhesion between monocytes and endothelial cells under intermittent hypoxia. J Cell Physiol. 2019;234(2):1512-21.

13. Serebrovska TV, Portnychenko AG, Drevytska TI, Portnichenko VI, Xi L,

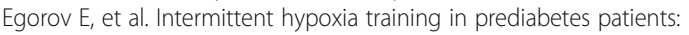
Beneficial effects on glucose homeostasis, hypoxia tolerance and gene expression. Ex Biol Med (Maywood). 2017;242:1542-52.

14. Costalat G, Lemaitre F, Tobin B, Renshaw G. Intermittent hypoxia revisited: a promising non-pharmaceutical strategy to reduce cardio-metabolic risk factors? Sleep Breath. 2018;22(1):267-71.

15. Manukhina EB, Downey HF, Shi X, Mallet RT. Intermittent hypoxia training protects cerebrovascular function in Alzheimer's disease. Ex Biol Med (Maywood). 2016;241:1351-63.

16. Ramond A, Godin-Ribuot D, Ribuot C, Totoson P, Koritchneva I, Cachot S, et al. Oxidative stress mediates cardiac infarction aggravation induced by intermittent hypoxia. Fundam Clin Pharmacol. 2013;27:252-61.

17. Milano G, Bianciardi P, Rochemont V, Vassalli G, Segesser LK, Corno AF, et al. Phosphodiesterase-5 inhibition mimics intermittent reoxygenation and improves cardioprotection in the hypoxic myocardium. PLoS One. 2011; 6(11):e27910.

18. Liberati A, Altman DG, Tetzlaff J, Mulrow C, Gotzsche PC, loannidis JP, et al. The PRISMA statement for reporting systematic reviews and meta-analyses of studies that evaluate healthcare interventions: explanation and elaboration. BMJ. 2009:339:b2700.

19. O'Connor D, Green S, Higgins JP. Cochrane Handbook for Systematic Reviews of Interventions. Chichester: Wiley. p. 81-94.

20. McGrath JC, Drummond GB, McLachlan EM, Kilkenny C, Wainwright CL. Guidelines for reporting experiments involving animals: the ARRIVE guidelines. Br J Pharmacol. 2010;160:1573-6.

21. Kilkenny C, Browne WJ, Cuthill IC, Emerson M, Altman DG. Improving bioscience research reporting: the ARRIVE guidelines for reporting animal research. J Pharmacol Pharmacother. 2010:1:94-9.

22. Macleod MR, O'Collins T, Howells DW, Donnan GA. Pooling of animal experimental data reveals influence of study design and publication bias. Stroke. 2004;35:1203-8

23. Crossley NA, Sena E, Goehler J, Horn J, van der Worp B, Bath PM, et al. Empirical evidence of bias in the design of experimental stroke studies: a metaepidemiologic approach. Stroke. 2008;39:929-34.

24. Li XY, Liu Y, Ma HJ, Guan Y, Cao Y, Tian YM, et al. Enhancement of glucose metabolism via PGC-1 alpha participates in the Cardioprotection of chronic intermittent hypobaric hypoxia. Front Physiol. 2016;7:219.

25. Meng XY, Yu HL, Zhang WC, Wang TH, Mai X, Liu HT, et al. ZFP580, a novel zinc-finger transcription factor, is involved in cardioprotection of intermittent high-altitude hypoxia against myocardial ischemia-reperfusion injury. PLoS One. 2014;9:e94635.

26. Ma HJ, Li Q, Ma HJ, Guan Y, Shi M, Yang J, et al. Chronic intermittent hypobaric hypoxia ameliorates ischemia/reperfusion-induced calcium overload in heart via $\mathrm{Na} / \mathrm{Ca}^{2+}$ exchanger in developing rats. Cell Physiol Biochem. 2014;34:313-24.

27. Gao L, Chen L, Lu ZZ, Gao H, Wu L, Chen YX, et al. Activation of a1Badrenoceptors contributes to intermittent hypobaric hypoxia-improved postischemic myocardial performance via inhibiting MMP-2 activation. Am J Physiol Heart Circ Physiol. 2014;306:H1569-81.

28. Manukhina EB, Belkina LM, Terekhina OL, Abramochkin DV, Smirnova EA, Budanova OP, et al. Normobaric, intermittent hypoxia conditioning is cardio- and vasoprotective in rats. Exp Biol Med (Maywood). 2013;238(12): 1413-20.

29. Wang ZH, Chen YX, Zhang CM, Wu L, Yu Z, Cai XL, et al. Intermittent hypobaric hypoxia improves postischemic recovery of myocardial contractile function via redox signaling during early reperfusion. Am J Physiol Heart Circ Physiol. 2011;301:H1695-705.

30. Belaidi E, Beguin PC, Levy P, Ribuot C, Godin-Ribuot D. Prevention of HIF-1 activation and iNOS gene targeting by low-dose cadmium results in loss of myocardial hypoxic preconditioning in the rat. Am J Physiol Heart Circ Physiol. 2008;294:H901-8. 
31. Yeung HM, Kravtsov GM, Ng KM, Wong TM, Fung ML. Chronic intermittent hypoxia alters $\mathrm{Ca} 2+$ handling in rat cardiomyocytes by augmented $\mathrm{Na}+$ / $\mathrm{Ca} 2+$ exchange and ryanodine receptor activities in ischemia-reperfusion. Am J Physiol Cell physiol. 2007;292:C2046-56.

32. Ravingerová T, Matejíková J, Neckáŕ J, Andelová E, Kolár F. Differential role of PI3K/Akt pathway in the infarct size limitation and antiarrhythmic protection in the rat heart. Mol Cell Biochem. 2007;297:111-20.

33. Kolár F, Jezkova J, Balkova P, Breh J, Neckar J, Novak F, et al. Role of oxidative stress in PKC-delta upregulation and cardioprotection induced by chronic intermittent hypoxia. Am J Physiol Heart Circ Physiol. 2007;292: H224-30.

34. Béguin PC, Belaidi E, Godin-Ribuot D, Levy P, Ribuot C. Intermittent hypoxiainduced delayed cardioprotection is mediated by PKC and triggered by p38 MAP kinase and Erk1/2. J Mol Cell Cardiol. 2007:42:343-51.

35. Zhu WZ, Xie Y, Chen L, Yang HT, Zhou ZN. Intermittent high altitude hypoxia inhibits opening of mitochondrial permeability transition pores against reperfusion injury. J Mol Cell Cardiol. 2006:40:96-106.

36. Kolár F, Neckar J, Ostadal B. MCC-134, a blocker of mitochondrial and opener of sarcolemmal ATP-sensitive K+ channels, abrogates cardioprotective effects of chronic hypoxia. Physiol Res. 2005;54:467-71.

37. Béguin PC, Joyeux-Faure M, Godin-Ribuot $D$, Lévy P, Ribuot C. Acute intermittent hypoxia improves rat myocardium tolerance to ischemia. J Appl Physiol. 2005;99:1064-9.

38. Joyeux-Faure M, Stanke-Labesque F, Lefebvre B, Béguin P, Godin-Ribuot D, Ribuot C, et al. Chronic intermittent hypoxia increases infarction in the isolated rat heart. J Appl Physiol. 2005;98:1691-6.

39. Neckár J, Markova I, Novak F, Novakova O, Szarszoi O, Ost'adal B, et al. Increased expression and altered subcellular distribution of PKC-delta in chronically hypoxic rat myocardium: involvement in cardioprotection. Am J Physiol Heart Circ Physiol. 2005;288:H1566-72.

40. Neckár J, Oštádal B, Kolár F. Myocardial infarct size-limiting effect of chronic hypoxia persists for five weeks of normoxic recovery. Physiol Res. 2004;53: 621-8.

41. Neckár J, Szárszoi O, Koten L, Papoušek F, Ošt'ádal B, Grover GJ, et al. Effects of mitochondrial KATP modulators on cardioprotection induced by chronic high altitude hypoxia in rats. Cardiovasc Res. 2002;55:567-75.

42. Neckár J, Papousek F, Novakova O, Ost'adal B, Kolar F. Cardioprotective effects of chronic hypoxia and ischaemic preconditioning are not additive. Basic Res Cardiol. 2002;97:161-7.

43. Heusch G. Molecular basis of Cardioprotection signal transduction in ischemic pre-, post-, and remote conditioning. Circ Res. 2015;116(4):674-99.

44. van Eickels M, Patten RD, Aronovitz MJ, Alsheikh-Ali A, Gostyla K, Celestin F, et al. 17-beta-estradiol increases cardiac remodeling and mortality in mice with myocardial infarction. J Am Coll Cardiol. 2003;41(11):2084-92.

45. Terrell AM, Crisostomo PR, Markel TA, Wang M, Abarbanell AM, Herrmann $\mathrm{JL}$, et al. Postischemic infusion of 17-beta-estradiol protects myocardial function and viability. J Surg Res. 2008;146:218-24.

46. de Almeida SA, Claudio ERG, Mengal V, Brasil GA, Merlo E, Podratz PL, et al. Estrogen therapy worsens cardiac function and remodeling and reverses the effects of exercise training after myocardial infarction in Ovariectomized female rats. Front Physiol. 2018;9:1242.

\section{Publisher's Note}

Springer Nature remains neutral with regard to jurisdictional claims in published maps and institutional affiliations.

Ready to submit your research? Choose BMC and benefit from:

- fast, convenient online submission

- thorough peer review by experienced researchers in your field

- rapid publication on acceptance

- support for research data, including large and complex data types

- gold Open Access which fosters wider collaboration and increased citations

- maximum visibility for your research: over $100 \mathrm{M}$ website views per year

At BMC, research is always in progress.

Learn more biomedcentral.com/submissions 